\title{
FAKTOR YANG BERHUBUNGAN DENGAN HAMBATAN PERILAKU PEMBERIAN ASI EKSKLUSIF DI WILAYAH KERJA PUSKESMAS ANGGERAJA KABUPATEN ENREKANG
}

\author{
Nur kalsum Mulsin ${ }^{1}$, Fatmah $^{2}$, Suriah $^{3}$ \\ ${ }^{1}$ Mahasiswa Pascasarjana Universitas Muslim Indonesia \\ ${ }^{2}$ Dosen Universitas Muslim Indonesia \\ ${ }^{3}$ Dosen Universiitas Hasanuddin
}

Alamat korespondensi : (kalsummulsin@gmail.com/085255500190)

\begin{abstract}
ABSTRAK
ASI eksklusif adalah pemberian ASI saja pada bayi sampai usia 6 bulan tanpa tambahan cairan ataupun makanan lain. Anak-anak yang mendapat ASI eksklusif 14 kali lebih mungkin untuk bertahan hidup dalam 6 bulan pertama kehidupan dibandingkan anak yang tidak disusui. Tujuan penelitian ini adalah untuk menganalisis faktor yang berhubungan dengan hambatan perilaku pemberian ASI eksklusif di wilayah kerja Puskesmas Anggeraja Kabupaten Enrekang. Penelitian ini menggunakan metode kuantitatif dengan desain penelitian Cross Sectional Study dan kualitatif dengan pendekatan fenomenologi. Populasi dalam penelitian ini adalah ibu yang memiliki anak usia 6-12 bulan dengan jumlah sampel sebanyak 110 orang. Sampel ditentukan menggunakan metode purposive sampling. Data diuji menggunakan uji Chi - Square. Dari hasil penelitian diperoleh bahwa variabel pengetahuan $p=0,003<0,05$, dukungan petugas kesehatan $p=0,015<0,05$, ada hubungan dengan hambatan perilaku pemberian ASI eksklusif di wilayah kerja Puskesmas Anggeraja Kabupaten Enrekang. Berdasarkan hasil temuan tersebut diharapkan pihak Puskesmas dapat mengembangkan informasi terkait pengetahuan, dukungan petugas kesehatan dalam meningkatkan perilaku pemberian ASI eksklusif.
\end{abstract}

Kata kunci: ASI eksklusif, Perilaku ibu, Enrekang.

\section{PENDAHULUAN}

Kesehatan merupakan investasi manusia yang tak ternilai. Investasi ini mendukung manusia untuk beraktivitas dengan optimal. Nutrisi yang baik berperan penting dalam kesehatan, terutama pada awal kehidupan, yaitu ketika bayi. Air susu ibu (ASI) merupakan makanan pertama, utama dan terbaik bagi bayi yang bersifat alamiah. ASI mengandung berbagai zat gizi yang dibutuhkan dalam proses pertumbuhan dan perkembangan bayi. Definisi World Health Organization (WHO) menyebutkan bahwa ASI eksklusif adalah ASI saja, tanpa cairan atau makanan padat apapun kecuali vitamin, mineral atau obat dalam bentuk tetes atau sirup sampai usia 6 bulan (WHO, 2009). Sejalan dengan hasil kajian WHO tersebut, Menkes melalui Kementerian kesehatan Republik Indonesia No.450/MENKES/IV/2004 yang menetapkan perpanjangan pemberian ASI secara eksklusif dari yang semula 4 bulan menjadi 6 bulan (Kemenkes, 2012).

Begitu pentingnya memberikan ASI kepada bayi tercermin pada rekomendasi Badan Kesehatan Dunia/World Health Organization (WHO) yang menghimbau agar setiap ibu memberikan ASI eksklusif sampai bayinya berusia enam bulan. Menurut data dari United Nations Children's Fund (UNICEF), anak-anak yang mendapat ASI eksklusif 14 kali lebih mungkin untuk bertahan hidup dalam enam bulan pertama kehidupan dibandingkan anak yang tidak disusui. Mulai menyusui pada hari pertama setelah lahir dapat mengurangi risiko kematian baru lahir hingga $45 \%$. Penelitian yang dilakukan Mgongo dkk., (2013) di Kilimanjaro Tanzaia menunjukkan bahwa EBF (Exclusive Breastfeeding) efektif untuk mencegah kematian balita hingga 13\% $15 \%$.

Berdasarkan riset di seluruh dunia, ASI merupakan makanan terbaik bagi bayi hingga enam bulan, dan disempurnakan hingga umur dua tahun. ASI, selain mengandung gizi yang cukup lengkap, mengandung imun untuk kekebalan tubuh bayi. Keunggulan lainnya, ASI disesuaikan dengan sistem pencernaan bayi sehingga zat gizi cepat terserap. Berbeda dengan susu formula atau makanan tambahan yang diberikan secara dini pada bayi. Susu formula sangat susah diserap usus bayi. Pada akhirnya, bayi sulit buang air besar. Apabila pembuatan susu formula tidak steril, bayi pun rawan diare. Kandungan gizinya pun tidak sama dengan kandungan gizi pada ASI 
(Menteri Negara Pemberdayaan Perempuan, 2012).

Data Riset Kesehatan Dasar (Riskesdas) tahun 2013 menunjukkan pemberian ASI di Indonesia saat ini memprihatinkan, persentase bayi yang menyusui eksklusif sampai dengan 6 bulan hanya $30,2 \%$. Hal ini disebabkan kesadaran masyarakat dalam mendorong peningkatan pemberian ASI masih relatif rendah (Riskesdas, 2013).

Berdasarkan data yang diperoleh dari Puskesmas Anggeraja pemberian ASI Eksklusif pada tahun 2016 ada 76,5\% yang ASI eksklusif dari 349 bayi. Sedangkan pada tahun 2017 ada $70,1 \%$ yang ASI eksklusif dari 317 bayi. Hal tersebut belum sesuai dengan target yang diharapkan oleh Departemen Kesehatan RI dimana ditargetkan pada tahun 2008, $80 \%$ wanita Indonesia sudah memberikan ASI eksklusif. Olehnya itu peneliti tertarik untuk meneliti apa saja faktor hambatan perilaku pemberian ASI Eksklusif di Puskesmas Anggeraja.

Berdasarkan uraian sebelumnya maka peneliti tertarik untuk melakukan penelitian dengan Judul "Faktor Yang Berhubungan Dengan Hambatan Perilaku Pemberian ASI Eksklusif Di Wilayah Kerja Puskesmas Anggeraja Kabupaten Enrekang"

\section{BAHAN DAN METODE}

Lokasi, Populasi, Sampel

Penelitian ini dilaksanakan di Kecamatan Anggeraja Wilayah Kerja Puskesmas Anggeraja pada bulan Oktober s/d November 2018. Populasi dalam penelitian ini sebanyak 151 ibu. Pada penelitian ini, peneliti menggunakan metode purposive sampling. Dengan Kriteria inklusi sebagai berikut :

1. Ibu yang memiliki bayi dari 6-12 bulan.

2. Bertempat tinggal di Kecamatan Anggeraja wilayah kerja Puskesmas Anggeraja.

Kriteria eksklusi diantaranya :

1. Pada penelitian ini adalah lbu yang tidak bisa menyusui dengan berbagai kondisi kesehatan yang tidak memungkinkan.

2. Ibu yang tidak bersedia menjadi responden.

\section{Pengumpulan Data}

1. In depth interview

Pewawancara membuat pedoman wawancara mendalam mengenai Faktor Yang Berhubungan Dengan Hambatan Perilaku Pemberian ASI Eksklusif Di wilayah Kerja Puskesmas Anggeraja Kabupaten Enrekang.

2. Dokumentasi
Dokumentasi dalam pengumpulan data dimaksud sebagai cara mengumpulkan dokument yang berbentuk gambar, video dan lain-lain serta mencatat bagian-bagian yang dianggap penting yang terdapat baik dilokasi penelitian maupun di instansi yang ada hubungannya dengan penelitian.

Pengolahan Data

1. Editing, yaitu mengkaji dan meneliti data yang telah terkumpulpada kuisioner.

2. Coding, yaitu memberikan kode pada data untuk memudahkan dalam memastikan data ke program komputer.

3. Entry, yaitu memasukan data kedalam program komputer untuk dianalisis selanjutnya.

4. Tabulating, yaitu setelah data masuk kemudian direkap dan disusun dalam bentuk tabel agar dapat dibaca dengan mudah.

5. Scoring, yaitu penentuan jumlah skor bila ada jawaban ya diberi skor 1 dan bila tidak diberi skor 0 .

\section{Teknik Analisis Data}

1. Analisis Univariat

Digunakan untuk mendeskripsikan variabel penelitian guna memperoleh gambaran atau karakteristik sebelum dilakukan analisis bivariat. Hasil dari penelitian ditampilkan dalam bentuk distribusi frekuensi.

2. Analisis Bivariat

Analisis bivariat yang dilakukan adalah tabulasi silang antara dua variabel yaitu variabel independen dan dependen. Analisis bivariat yang digunakan untuk mengetahui hubungan terhadap objek penelitian adalah menggunakan uji chisquare.

\section{HASIL PENELITIAN}

1. Analisis Univariat

Tabel 1 Distribusi Karakteristik Responden di Wilayah Kerja Puskesmas Anggeraja Kabupaten Enrekang Tahun 2018

\begin{tabular}{|c|c|c|}
\hline Karakteristik & $\mathrm{n}$ & $\%$ \\
\hline Umur Ibu & 9 & \\
$16-20$ Tahun & 20 & 8,2 \\
$21-25$ Tahun & 41 & 37,2 \\
$26-30$ Tahun & 29 & 26,4 \\
$31-35$ Tahun & 9 & 8,2 \\
36-40 Tahun & 2 & 1,8 \\
$\geq 41$ Tahun & & \\
Alamat Ibu & 29 & 26,4 \\
BT. NONI & 6 & 5,5 \\
LAKAWAN & 15 & 13,6 \\
SINGKI & 23 & 20,9 \\
SIAMBO & 11 & 10,0 \\
TINDALUN & 14 & 12,7 \\
TANETE & \multicolumn{2}{|l}{}
\end{tabular}




\begin{tabular}{|l|c|c|}
\hline SARURAN & 1 & 0,09 \\
TAMPO & 11 & 10,0 \\
\hline Pendidikan Ibu & & \\
SD & 16 & 14,5 \\
SMP & 15 & 13,6 \\
SLTA & 47 & 42,7 \\
D3 & 10 & 9,1 \\
D4/S1/S2 & 22 & 20,0 \\
\hline Umur Anak (Bulan) & & \\
6 & 25 & 22,7 \\
7 & 15 & 13,6 \\
8 & 15 & 13,6 \\
9 & 9 & 8,2 \\
10 & 9 & 8,2 \\
11 & 6 & 5,5 \\
12 & 31 & 28,2 \\
\hline
\end{tabular}

Dari tabel 1 distribusi responden berdasarkan umur ibu menunjukkan bahwa sebagian besar ibu $26-30$ tahun sebanyak 41 (60,9\%). Sedangkan lebih sedikit pada umur $\geq 41$ tahun yaitu 2 $(1,8 \%)$. Distribusi responden berdasarkan alamat ibu maka menunjukkan bahwa ibu bertempat tinggal di desa Bt. Noni sebanyak 29 (26,4\%), di desa Lakawan sebanyak $6 \quad(5,5 \%)$, di desa Singki sebanyak $15(13,6 \%)$, di desa Siambo sebanyak $23(20,9 \%)$, di desa Tindalun sebanyak $11(10,0 \%)$, di desa Tanete sebanyak $14(12,7 \%)$, di desa Saruran sebanyak $1(0,9 \%)$, dan di desa Tampo sebanyak $11(10,0 \%)$. Distribusi responden berdasarkan pendidikan terakhir ibu menunjukkan pendidikan terakhir ibu yang tertinggi yaitu SLTA sebanyak 47 (42,7\%). Sedangkan pendidikan terakhir ibu yang terendah yaitu D3 sebanyak $10 \quad(9,1 \%)$. Distribusi responden berdasarkan umur anak menunjukkan bahwa sebagian besar ibu memiliki anak berumur 12 bulan yaitu sebanyak $31(28,2 \%)$. Dan sebagian kecil memiliki anak berumur 11 bulan yaitu 6 $(5,5 \%)$.

2. Analisis Bivariat

Tabel 2 Distribusi Responden Berdasarkan Hubungan Pengetahuan dengan Perilaku Pemberian ASI Eksklusif di Wilayah Kerja Puskesmas Anggeraja Kabupaten Enrekang Tahun 2018

\begin{tabular}{|c|c|c|c|c|c|c|}
\hline \multirow{3}{*}{$\begin{array}{l}\text { Pengeta } \\
\text { huan }\end{array}$} & \multicolumn{4}{|c|}{$\begin{array}{c}\text { Perilaku pemberian ASI } \\
\text { Eksklusif }\end{array}$} & \multirow{2}{*}{\multicolumn{2}{|c|}{ Total }} \\
\hline & \multicolumn{2}{|c|}{$\begin{array}{c}\text { Tidak } \\
\text { Eksklusif }\end{array}$} & \multicolumn{2}{|c|}{ Eksklusif } & & \\
\hline & $\mathrm{n}$ & $\%$ & $\mathrm{n}$ & $\%$ & $\mathrm{n}$ & $\%$ \\
\hline Kurang & 36 & 97,3 & 1 & 2,7 & 37 & 100,0 \\
\hline Cukup & 54 & 74,0 & 19 & 26,0 & 73 & 100,0 \\
\hline Total & 90 & 81,8 & 20 & 18,2 & 110 & 100,0 \\
\hline \multicolumn{7}{|c|}{$p$ Value $=0,003$} \\
\hline
\end{tabular}

Berdasarkan tabel 2 distribusi responden berdasarkan pengetahuan ibu menunjukkan bahwa ibu yang memiliki tingkat pengetahuan kurang yang tidak ASI Eksklusif sebanyak $36(97,3 \%)$ dan ASI Eksklusif sebanyak 1 (2,7\%), sedangkan ibu yang memiliki pengetahuan cukup yang tidak ASI Eksklusif sebanyak 54 (74,0\%) dan ASI Eksklusif sebanyak 19 (26,0\%). Berdasarkan hasil uji statistik dengan menggunakan Uji Chi Square diperoleh nilai $p=0,003<0,05$ yang berarti bahwa ada hubungan yang signifikan antara pengetahuan dengan perilaku pemberian ASI Eksklusif di wilayah kerja Puskesmas Anggeraja Kabupaten Enrekang Tahun 2018.

Hasil di atas didukung oleh hasil wawancara dengan beberapa informan sebagai berikut : "....manfaat ASI eksklusif menurutku sistim kekebalan tubuhnya bagus. Diberikan kepada anak sampai 6 bulan bisa juga sampai 2 tahun. Dan yang kudengar dari biasa bidan lebih bagus ASI eksklusif, asi eksklusif itu langsung dikasih saja dan tidak anu juga biayanya...."

(Informan V, 25 tahun, 28 November 2018) “....menurutku saya asi eksklusif daya tahan tubuhnya lebih bagus, jarang sakit juga dan juga lebih mudah tidak repot mi baru lebih bersih juga . biasa ada orang baru lahir itu kasi madu na itu tidak bole dikasi untuk anak. Baru ku kasi anakku bubur umur 6 bulanpi ke atas...."

(Informan R, 32 tahun, 28 November 2018)

Tabel 3 Distribusi Responden Berdasarkan Hubungan Dukungan Petugas Kesehatan dengan Perilaku Pemberian ASI Eksklusif di Wilayah Kerja Puskesmas Anggeraja Kabupaten Enrekang Tahun 2018

\begin{tabular}{|c|c|c|c|c|c|c|}
\hline \multirow{4}{*}{$\begin{array}{c}\text { Dukungan } \\
\text { Petugas } \\
\text { Kesehatan }\end{array}$} & \multicolumn{2}{|c|}{$\begin{array}{c}\text { Perilaku pemberian } \\
\text { ASI Eksklusif }\end{array}$} & \multicolumn{2}{|c|}{} \\
\cline { 2 - 6 } & $\begin{array}{c}\text { Tidak } \\
\text { Eksklusif }\end{array}$ & \multicolumn{2}{|c|}{$\begin{array}{c}\text { Eksklu } \\
\text { sif }\end{array}$} & \multicolumn{2}{|c|}{ Total } \\
\cline { 2 - 7 } & $\mathrm{n}$ & $\%$ & $\mathrm{n}$ & $\%$ & $\mathrm{n}$ & $\%$ \\
\hline $\begin{array}{c}\text { Tidak Mendu } \\
\text { kung }\end{array}$ & 19 & 100,0 & 0 & 0 & 19 & 100,0 \\
\hline Mendu kung & 71 & 78,0 & 20 & 22,0 & 92 & 100,0 \\
\hline Total & 90 & 81,8 & 20 & 18,2 & 110 & 100,0 \\
\hline \multicolumn{6}{|c|}{$p$ Value $=0,015$} \\
\hline
\end{tabular}

Berdasarkan tabel 3 distribusi responden berdasarkan dukungan petugas kesehatan menunjukkan bahwa dukungan petugas kesehatan yang tidak mendukung yang tidak ASI Eksklusif sebanyak 19 $(100,0)$ dan yang ASI Eksklusif sebanyak 0 $(, 0 \%)$, sedangkan yang mendukung yang tidak ASI Eksklusif sebanyak 71 (78,0\%) dan yang ASI Eksklusif sebanyak 20 
$(22,0 \%)$. Berdasarkan hasil uji statistik dengan menggunakan Uji Chi Square diperoleh $p=0,015<0,05$ yang berarti ada hubungan dukungan petugas kesehatan dengan perilaku pemberian ASI Eksklusif di wilayah kerja Puskesmas Anggeraja Kabupaten Enrekang Tahun 2018.

Berdasarkan hasil di atas, peneliti juga menambahkan hasil wawancara dengan beberapa informan, sebagai berikut :

“....jarang dikasi penyuluhan tentang asi kalau datang ke posyandu hanya di kasi tau saja bilang kasi anak ta asi eksklusif sampai umur enam bulan, dan juga tidak perna ada petugas kesehatan yang berkunjung kerumah. Kalaupun pergika ke tempat praktek bidan dia juga yang tanyaka kasi asi anakku kah sedikitji asiku keluar memang tapi selalu nakasi ingatka bilang kasi asi sampai enam bulanki..." (Informan V, 25 tahun, 28 November 2018)

\section{PEMBAHASAN}

1. Hubungan Pengetahuan lbu terhadap Perilaku Pemberian ASI Eksklusif

Pengetahuan merupakan hasil dari tahu dan hal ini terjadi setelah orang melakukan penginderaan terhadap suatu obyek tertentu. Penginderaan terjadi melalui panca indera manusia yaitu indera penglihatan, pendengaran, penciuman, rasa dan raba, sebagian besar pengetahuan manusia dapat diperoleh melalui mata dan telinga (Notoatmodjo, 2012).

Berdasarkan hasil penelitian dengan menggunakan uji statistik Chi Square diperoleh $p$ value $=0,003$, karena nilai $p$ $<0,05$ dengan derajat kemaknaan $\alpha=0,05$ maka hipotesis nol ditolak dan hipotesis alternatif diterima yang artinya ada hubungan yang bermakna antara pengetahuan terhadap perilaku pemberian ASI Eksklusif pada ibu di wilayah kerja Puskesmas Anggeraja Kabupaten Enrekang.

Hasil penelitian ini menunjukkan dari 110 responden, yang memiliki pengetahuan cukup sebanyak $73(66,4 \%)$ dan yang memiliki pengetahuan kurang sebanyak $37(33,6 \%)$.

Menurut hasil penelitian dilapangan, sebagian besar responden yang memberikan ASI eksklusif untuk anaknya dikarenakan mereka sudah merasakan manfaat pemberian ASI eksklusif itu sendiri terhadap bayinya khususnya sistem imun bayi yang diberikan ASI eksklusif meningkat dibandingkan dengan bayi yang diberikan susu formula.

Pengetahuan yang didapatkan sebagian besar ibu berasal dari pengalaman menyusui anak sendiri dan perilaku menyusui keluarganya yang lain dan orang sekitar, pengetahuan ibu juga cenderung didapatkan dari beberapa informasi dari petugas kesehatan, media, dan sumber informasi yang mendukung lainnya sehingga responden memiliki kesadaran dalam memberikan ASI eksklusif kepada bayinya, beberapa informasi yang didapatkan dilapangan oleh peneliti ternyata hasil ini sejalan dengan yang dikemukakan oleh Mukhoirotin (2015) bahwa pengetahuan merupakan faktor predisposisi terhadap perubahan perilaku yang mengarahkan pada peningkatan status kesehatan. Termasuk perilaku ibu dalam memenuhi kebutuhan ASI kepada bayinya Perilaku yang didasari oleh pengetahuan, kesadaran dan sikap yang positif maka perilaku tersebut akan bersifat langgeng (long lasting). Sebaliknya apabila perilaku itu tidak didasari oleh pengetahuan dan kesadaran akan tidak berlangsung lama.

2. Hubungan dukungan petugas kesehatan terhadap Perilaku Pemberian ASI Eksklusif

Setiap kontak yang dimiliki oleh seseorang petugas kesehatan dengan seorang lbu adalah merupakan kesempatan untuk mendorong dan mempertahankan perilaku menyusui. Pemantauan pertumbuhan dan perkembangan adalah cara untuk mengetahui apakah bayi cukup mendapatkan ASI (Depkes, 2007).

Dari hasil penelitian didapatkan dukungan petugas kesehatan yang mendukung yang memberikan ASI eksklusif sebanyak 22,0\% dan yang tidak memberikan ASI eksklusif sebanyak $78,0 \%$. Sedangkan dukungan petugas kesehatan yang tidak mendukung yang memberikan ASI eksklusif sebanyak ,0\% dan yang tidak ASI eksklusif sebanyak $100 \%$.

Berdasarkan hasil uji statistic menggunakan Chi Square maka diperoleh $p$ value $=0,015$, karena nilai $p<0,05$ dengan derajat kemaknaan $\alpha=0,05$ maka hipotesis nol ditolak dan hipotesis alternatif diterima yang artinya ada hubungan yang bermakna antara dukungan petugas kesehatan terhadap perilaku pemberian ASI eksklusif diwilayah kerja Puskesmas Anggeraja Kabupaten Enrekang.

Menurut hasil penelitian di lapangan, petugas kesehatan cukup berperan aktif 
terhadap perilaku ibu dalam memberikan ASI eksklusif karena petugas kesehatan dianggap orang yang lebih mengerti tentang pemberian ASI eksklusif, petugas kesehatan juga hampir tiap bulan melakukan pemberikan pendidikan kesehatan terkait pentingnya memberikan ASI eksklusif kepada bayi sehingga hampir semua ibu sudah tahu tentang pemberian ASI eksklusif. Selain itu petugas kesehatan juga selalu mengajarkan kepada ibu-ibu yang baru pertama kali mempunyai bayi tentang cara memompa ASI dengan benar dan cara pemberian ASI kepada bayi.

Berdasarkan Keputusan Menteri

Kesehatan RI No

450/MENKES/SK/IV/2004 tentang

pemberian ASI secara eksklusif butir b menyatakan semua tenaga kesehatan yang bekerja di sarana pelayanan kesehatan agar menginformasikan kepada semua ibu yang baru melahirkan untuk memberikan ASI eksklusif. Informasi dan dukungan tenaga kesehatan tentang ASI eksklusif bisa menambah pengetahuan ibu, sehingga ibu mempunyai motivasi untuk memberikan ASI eksklusif.

\section{KESIMPULAN}

1. Ada hubungan pengetahuan dengan hambatan perilaku pemberian ASI eksklusif, dengan nilai $p=0,003(p<0,05)$.

2. Ada hubungan dukungan petugas kesehatan dengan hambatan perilaku pemberian ASI eksklusif, dengan nilai $p=$ $0,015(p<0,05)$.

\section{SARAN}

1. Dalam penelitian ini ditemukan bahwa ada hubungan pengetahuan dengan perilaku pemberian ASI eksklusif sehingga pihak puskesmas dapat mengadakan edukasi tentang pentingnya menyusui.

2. Perlunya pihak puskesmas mengadakan program yang melibatkan keluarga dalam mendukung pemberian ASI yaitu kelompok suami pendukung ASI dan gerakan peduli ASI.

\section{DAFTAR PUSTAKA}

A.A Istri Hiranya, I.A Eka Padmiari. 2015. Faktor-Faktor Yang Mempengaruhi Keberhasilan ASI Eksklusif Di Wilayah Kerja Puskesmas 1 Denpasar Timur Tahun 2015, Jurnal Virgin, Vol. 1 (2), pp. 177-190.

Adila, Sandra, dan Ahmad Tahun 2013. ASI Eksklusif Dan Persepsi Ketidakcukupan ASI Tahun 2013. Jurnal Kesehatan Masyarakat Nasional, Vol. 9 (3), pp. 282-287.

Arifa, Shrimarti, dan Rukmini Tahun 2016. Faktor Yang Mempengaruhi Niat Ibu Memberikan ASI Eksklusif Di Kelurahan Magersari Sidoarjo Tahun 2016. Jurnal Promosi Kesehatan, Vol. 4 (1), pp. 11-21.

Bayu Kurniawan Tahun 2013. Determinan Keberhasilan Ibu Eksklusif Tahun 2013. Jurnal Kedokteran Brawijaya, Vol. 27 (4), pp. 236-240.

Dwi Kurniawati, Rachmat Hargono Tahun 2104. Faktor Determinan Yang Mempengaruhi Kegagalan Pemberian ASI Eksklusif Pada Bayi Usia 6-12 Bulan Di Kelurahan Mulyorejo Wilayah Kerja Puskesmas Mulyorejo Surabaya Tahun 2014. Jurnal Promosi Kesehatan, Vol. 2 (1), pp. 15-27.

Herlina Susmaneli, 2013. Faktor-Faktor Yang Berhubungan Dengan Pemberian ASI Eksklusif Di Wilayah Kerja Puskesmas Rambah Hilit 1 Kabupaten Rokan Hulu Tahun 2012. Jurnal Kesehatan Komunitas, Vol.2 (2), Mei 2013, pp: 67-71.

$\begin{array}{llll}\text { Kemenkes, } & 2012 . & \text { Manfaat } & \text { ASI, (Online). }\end{array}$ (http://www.bppsdmk.depkes.go.id/index.php?option=com_content\&view=article\&id=170:banyak-sekalimanfaat-asi-bagi-bayi-dan-ibu\&catid=38:berita\&ltemid=82, Diakses tanggal 18 agustus 2018.

Mukhoirotin, 2015. Hubungan Pengetahuan Ibu tentang ASI Eksklusif Dengan Perilaku Pemberian ASI Eksklusif di BPM HJ. UMI SALAMAH PETERONGAN JOMBANG Tahun 2015. Jurnal Edu Health, Vol 5 (2), September 2015.

Notoatmodjo S, 2012. IImu Perilaku Kesehatan. Rineka Cipta, Jakarta.

Riskesdas, 2010. Riset Kesehatan Dasar Tahun 2010. Jakarta: Badan Penelitian Dan Pengembangan Kesehatan Kementrian Kesehatan RI.

WHO \& UNICEF (2006) Global Strategy: Breastfeeding Critical for Chld Survival, New Work: WHO/UNICEF. 